\title{
An Implantable Stimulator With Safety Sensors in Standard CMOS Process for Active Books
}

\author{
Xiao Liu, Member, IEEE, Virgilio Valente, Member, IEEE, Zhulin Zong, Member, IEEE, \\ Dai Jiang, Member, IEEE, Nick Donaldson, and Andreas Demosthenous, Senior Member, IEEE
}

\begin{abstract}
This paper presents a second-generation integrated circuit for the Active Books neural stimulation microsystem. It provides multi-channel stimulation with versatile control of stimulation profiles and reduced crosstalk from other stimulation channels. The new design features enhanced safety by monitoring the temperature and humidity inside the micropackage, and the peak electrode voltage at any stimulating electrode. The humidity sensor uses an interdigitated capacitor covered by a passivation layer and a polyimide covering. To boost sensitivity in the operating range of interest, the temperature sensor uses a temperature-insensitive current that is subtracted from a proportional-to-absolute-temperature current. A 3-b analog-todigital converter is used to record the peak electrode voltage. All sensor data is sent to an implanted central hub using bidirectional connection with error checking. Both the stimulation electronics and sensors are integrated on a $6.2 \mathrm{~mm} \times 4 \mathrm{~mm}$ silicon die using XFAB's 0.6- $\mu \mathrm{m}$ CMOS high-voltage process. No post-processing steps are involved. The stimulator uses a fivewire cable to provide the power supply and bidirectional data signals. The chip operates from a 7.5-18 V power supply and can generate stimulation currents of $1 \mathrm{~mA}, 4 \mathrm{~mA}$ or $8 \mathrm{~mA}$ with a pulse duration of $2 \mu \mathrm{s}-1.07 \mathrm{~ms}$. The humidity sensor output varies linearly with relative humidity (RH) with a normalized sensitivity of $0.04 \% / \% \mathrm{RH}$ over the range of $20-90 \% \mathrm{RH}$. The temperature sensor has a nonlinearity of $0.4 \%$ over the range of $20-90{ }^{\circ} \mathrm{C}$ and a resolution of $0.12{ }^{\circ} \mathrm{C}$. The stimulator is the first of its kind to include integrated temperature and humidity sensors.

Index Terms-Active Books, humidity sensor, implant safety, integrated stimulator, temperature sensor, voltage sensor.
\end{abstract}

\section{INTRODUCTION}

$\mathbf{R}$ ECENT progress in biomedical science and neural engineering, especially in disciplines involving neuroprostheses, has been facilitated by rapid advances in integrated circuit and microfabrication technologies [1]. Implanted devices using integrated circuits, ranging from neuromuscular stimulators [2], to neural amplifiers including those with

Manuscript received April 10, 2016; accepted May 24, 2016. Date of publication June 7, 2016; date of current version September 1, 2016. This work was supported by the U.K. Engineering and Physical Sciences Research Council (EPSRC) under Grant EP/F009593/1. The associate editor coordinating the review of this paper and approving it for publication was Dr. Patrick Ruther.

X. Liu, V. Valente, D. Jiang, and A. Demosthenous are with the Department of Electronic and Electrical Engineering, University College London, London WC1E 7JE, U.K. (e-mail: xiao@ucl.ac.uk; v.valente@ucl.ac.uk; d.jiang@ucl.ac.uk; a.demosthenous@ucl.ac.uk).

Z. Zong was with the Department of Electronic and Electrical Engineering, University College London, London WC1E 7JE, U.K. He is now with the University of Electronic Science and Technology of China, Chengdu 611731, China (e-mail: zongzhulin@uestc.edu.cn).

N. Donaldson is with the Department of Medical Physics and Bioengineering, University College London, London WC1E 6BT, U.K. (e-mail: n.donaldson@ucl.ac.uk).

Digital Object Identifier 10.1109/JSEN.2016.2577688 processing capabilities (e.g., spike detection [3] and wireless transmission [4]) are continually emerging. Implanted devices require exceptional safety precautions. This demands monitoring and assessment of such devices and the possible impact on the neural system should they fail. The following considerations are important:

1. The biological fluid is highly corrosive and any imperfection in the hermetic seal of the package can gradually introduce moisture onto the active circuits. Condensation can bridge conductor lines causing electrolytic reactions, short-circuits or corrosion [5]-[7].

2. For an implantable stimulator, the highest power consumption tends to occur when the stimulator output stage is in operation. Most stimulator output stages are implemented using current-mode circuits and hence the power consumption is usually proportional to the supply voltage. Besides the energy that is converted to ionic movement at the electrode-tissue interface (for eliciting the desired neural actions), the rest of the electrical energy is converted to heat inside the chip. The human body is a well-regulated system with a stable temperature around $37^{\circ} \mathrm{C}$. If the heat dissipated by the implant raises the local temperature of nearby tissue by more than a few degrees, it could cause irreversible damage to the neural tissue [8]. Using the lowest possible supply voltage for the required current drive from the stimulator circuits minimizes heat dissipation into the neural tissue.

3. Both mechanical and electrical failures can occur in implanted devices [9]. In the case of mechanical failure, for example, loose or broken connections between parts [10], [11] or insulation failure at the cable [12] could expose the neural tissue to dangerous voltages. In terms of electrical failure, malfunctioning of digital control [13], vulnerability of analog electronics or other reliability issues associated with semiconductors chips [14]-[19] could potentially compromise the longterm safety of the neural environment. Electrical failure in an implantable stimulator could interrupt the charge balance necessary for safe stimulation. This could cause electrolysis to occur at the electrodes and harmful byproducts to be generated as a result of net direct current stimulation [20], [21].

To ensure optimum safety conditions, in addition to charge balance [2], monitoring of temperature [8], humidity [22] and electrode voltage [23] is necessary. To minimize the total 


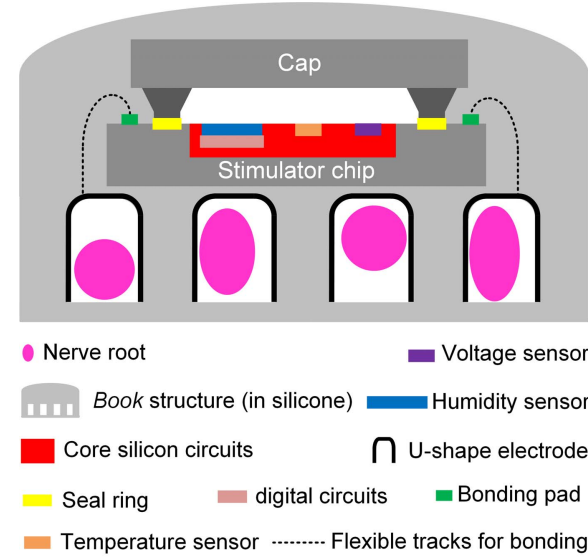

Fig. 1. Concept diagram of the Active Book (cross-sectional view) with its embedded stimulator chip featuring humidity, temperature and voltage sensors. The diagram is not to be scaled.

implant size the sensors must be an integral part of the (CMOS) stimulation electronics.

In [24], the authors proposed a distributed neural stimulation system using Active Books that interface with nerve roots in the cauda equina. Stimulation of these nerves aims to restore lower-limb function in paraplegic spinal cord injured patients. To improve safety, in this paper the stimulator chip inside an Active Book (see Fig. 1) has been modified to include: i) a humidity sensor to monitor the relative humidity inside the micropackage, ii) a temperature sensor to check overheating after lengthy stimulation, and iii) a voltage sensor to monitor the peak voltage on any specified stimulating electrode to minimize power consumption (and thus heat dissipation). For monitoring purposes in active implantable microsystems, it is the relative changes in temperature and humidity (and not their absolute values) that are important in order to trigger an alarm.

Unlike [24] the added humidity sensor was placed on top of the digital circuits to make the stimulator chip compact. To the authors' best knowledge, this is the first stimulator chip featuring integrated temperature and humidity sensors.

This paper describes the design, implementation and evaluation of the modified stimulator chip for Active Books focusing on the safety sensors and their performance. Section II provides an overview of the stimulator architecture and functionality. Section III describes methods for integrated capacitive humidity sensors in CMOS technology (both standard CMOS and those requiring custom post-processing), and the readout circuit of the designed humidity sensor. Sections IV and V describe the temperature and voltage sensors, respectively. Experimental evaluation of the fabricated stimulator chip including the performance of the safety sensors and comparison with other work, are presented in Section VI. Section VII concludes the paper.

\section{Stimulator ARChitecture}

Fig. 2 shows the block diagram of the modified stimulator chip with the added sensors highlighted. It uses a 5-wire cable to provide an adjustable supply voltage ( $V_{\mathrm{DDA}}$ and $\left.V_{\mathrm{SS}}\right)$ and bidirectional data signals (INOUT, CLOCK and ENABLE).
The cable connects to the central hub which supervises the operation of up to four Active Books [24], yielding sixteen stimulating tripoles (four per Active Book). The data signal INOUT is specific to each Active Book (the others are common to all chips). It is used for addressing the chosen Active Book and carries the sensors data to the central hub for monitoring. The chip remains in the quiescent mode, consuming negligible power, until the control signals follow a specific 'wake-up' sequence. Once alerted, the chip is programmed for various functions using pulse trains on the CLOCK line as detailed in [24]. Each train can have up to twenty-one pulses. A sequence of pulse trains of different lengths has a specific meaning. Commands supported by the chip are listed in Table I with their respective train sequences.

The supply voltage on the $V_{\text {DDA }}$ line is adjusted in the central hub to the minimum value necessary to drive the (variable) electrode load. The voltage level necessary depends on the electrode impedance and stimulus current. A high-voltage $V_{\text {DDA }}$ is required for stimulus current of high amplitude flowing through a large electrode impedance. The on-chip voltage sensor samples the electrode voltage during stimulation and feeds back the information to the central hub, which adjusts the $V_{\mathrm{DDA}}$ accordingly to minimize the power consumption of the stimulator chip. The $5 \mathrm{~V}$ regulator provides the supply voltage for the digital circuits (e.g., command interpreter unit) and the low-voltage analog circuits (e.g., the readout circuits of the sensors). The command interpreter unit in Fig. 2 instructs the appropriate parts of the chip for sensing or stimulationrelated functions. The analog output of the temperature sensor is digitized by a 10-bit successive approximation register (SAR) analog-to-digital converter (ADC) before it is modulated using a constant-weight $m$-of- $n$ code scheme, which allows for detection of single-bit errors [24]. The required clock signals for the ADC and modulation are provided by an on-chip RC oscillator. When not needed the oscillator is disabled to conserve power. The temperature sensor unit also provides a temperature-independent reference current which is used in the stimulator output stage and humidity sensor. The on-chip humidity sensor converts the change of humidity-sensitive capacitance to freqeuency, which is then converted to a numerical value, before being modulated onto the INOUT line.

\section{Humidity SENSOR}

The change of relative humidity can be sensed by a change of resistance or capacitance. The capacitance change is often preferred because it consumes no static power and is less influenced by temperature variations compared to resistance change. A capacitive humidity sensor can be realized with a moisture sensing film (dielectric layer) either sandwiched between two parallel plates or deposited on top of interdigitated electrodes. Polyimide is a popular choice for sensing material due to its extensive use in the semiconductor industry. Fig. 3 shows various approaches to implementing the sensing capacitor in CMOS, all requiring some post processing to remove the passivation layer and deposit the humidity sensing layer [22], [25]-[28]. The approaches in Figs 3(a) [22], 3(b) [25] and 3(c) [26] are more complex than 


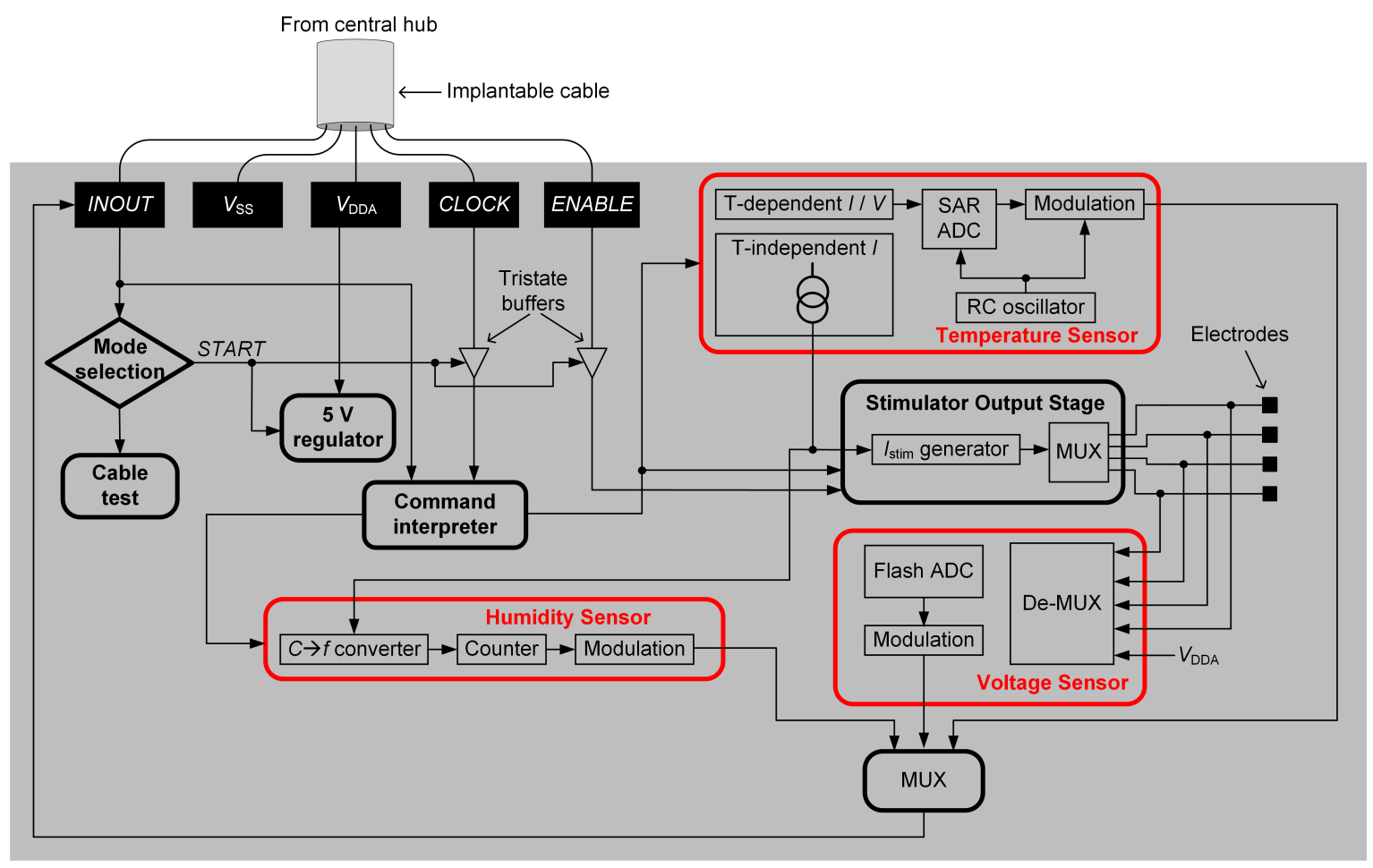

Fig. 2. Functional block diagram of the stimulator chip for Active Books with the sensors highlighted.

TABLE I

COMMANDS SUPPORTED B Y THE STIMUlator ChiP

\begin{tabular}{|c|c|c|c|c|c|c|c|c|c|c|}
\hline \multirow{2}{*}{\multicolumn{3}{|c|}{ Command }} & \multicolumn{8}{|c|}{ Train sequence $^{1}$} \\
\hline & & & $1^{\text {st }}$ train & $2^{\text {nd }}$ train & $3^{\text {rd }}$ train & $4^{\text {th }}$ train & $5^{\text {th }}$ train & $6^{\text {th }}$ train & $7^{\text {th }}$ train & $8^{\text {th }}$ train \\
\hline \multirow{4}{*}{$\begin{array}{l}\text { Change current } \\
\text { amplitude }\end{array}$} & \multicolumn{2}{|l|}{ to $0 \mathrm{~mA}$} & \multirow{4}{*}{$\mathrm{X} 21$} & \multirow{4}{*}{$\mathrm{X} 20$} & \multirow{4}{*}{$\mathrm{X} 18$} & $\mathrm{X} 18$ & \multirow{4}{*}{$\mathrm{X} 17$} & & & \\
\hline & \multicolumn{2}{|l|}{ to $1 \mathrm{~mA}$} & & & & $\mathrm{X} 19$ & & & & \\
\hline & \multicolumn{2}{|l|}{ to $4 \mathrm{~mA}$} & & & & $\mathrm{X} 20$ & & & & \\
\hline & \multicolumn{2}{|l|}{ to $8 \mathrm{~mA}$} & & & & $\mathrm{X} 21$ & & & & \\
\hline \multirow{11}{*}{$\begin{array}{l}\text { Change anode } \\
\text { current ratio }\end{array}$} & of Slot 1 & to $0 \%$ & \multirow{11}{*}{$\mathrm{X} 21$} & \multirow{11}{*}{$\mathrm{X} 20$} & \multirow{11}{*}{ X19 } & \multirow{8}{*}{$\mathrm{X} 18$} & $\mathrm{X} 18$ & $\mathrm{X} 18$ & $\mathrm{X} 18$ & \multirow{11}{*}{$\mathrm{X} 17$} \\
\hline & of Slot 1 & to $2 \%$ & & & & & \multirow{4}{*}{ X19 } & $\mathrm{X} 18$ & $\mathrm{X} 18$ & \\
\hline & of Slot 1 & to $4 \%$ & & & & & & $\mathrm{X} 18$ & X19 & \\
\hline & of Slot 1 & $\ldots$ & & & & & & $\ldots$ & $\ldots$ & \\
\hline & of Slot 1 & to $20 \%$ & & & & & & $\mathrm{X} 20$ & X19 & \\
\hline & of Slot 1 & to $-2 \%$ & & & & & \multirow{3}{*}{$\mathrm{X} 20$} & $\mathrm{X} 18$ & $\mathrm{X} 18$ & \\
\hline & of Slot 1 & $\ldots$ & & & & & & $\ldots$ & $\ldots$ & \\
\hline & of Slot 1 & to $-20 \%$ & & & & & & $\mathrm{X} 20$ & X19 & \\
\hline & of Slot 2 & $\ldots$ & & & & $\mathrm{X} 19$ & $\ldots$ & $\ldots$ & $\ldots$ & \\
\hline & of Slot 3 & $\ldots$ & & & & $\mathrm{X} 20$ & $\ldots$ & $\ldots$ & $\ldots$ & \\
\hline & of Slot 4 & $\ldots$ & & & & $\mathrm{X} 21$ & $\ldots$ & $\ldots$ & $\ldots$ & \\
\hline \multirow{2}{*}{ Sensor readout } & \multicolumn{2}{|c|}{ Measure humidity } & \multirow{2}{*}{$\mathrm{X} 19$} & \multirow{2}{*}{$\mathrm{X} 18$} & $\mathrm{X} 18$ & \multirow{2}{*}{$\mathrm{X} 17$} & & & & \\
\hline & Measure & nperature & & & $\mathrm{X} 19$ & & & & & \\
\hline \multirow{6}{*}{$V_{\mathrm{DDA}}$ adjustment } & \multicolumn{2}{|c|}{ Measure $V_{\mathrm{DDA}}$} & \multirow{6}{*}{$\mathrm{X} 19$} & $\mathrm{X} 19$ & $\mathrm{X} 17$ & & & & & \\
\hline & \multirow{5}{*}{$\begin{array}{l}\text { Measure } \\
\text { anode }\end{array}$} & Slot 1's Anode 1 & & \multirow{5}{*}{$\mathrm{X} 20$} & \multirow{2}{*}{$\mathrm{X} 18$} & $\mathrm{X} 18$ & & & & \\
\hline & & Slot 2's Anode 2 & & & & $\mathrm{X} 19$ & & & & \\
\hline & & $\ldots$ & & & $\ldots$ & .. & X17 & & & \\
\hline & & Slot 4's Anode 1 & & & & $\mathrm{X} 18$ & & & & \\
\hline & & Slot 4's Anode 2 & & & $X 21$ & $\mathrm{X} 19$ & & & & \\
\hline Do not measure ( & & & $\mathrm{X} 19$ & $\mathrm{X} 21$ & $\mathrm{X} 21$ & $\mathrm{X} 17$ & & & & \\
\hline Reset all control & puts & & $\mathrm{X} 21$ & $\mathrm{X} 20$ & $\mathrm{X} 21$ & $\mathrm{X} 21$ & $\mathrm{X} 17$ & & & \\
\hline
\end{tabular}

${ }^{1}$ The length of each train in a train sequence is denoted by $\mathrm{X} n$, where $n$ indicates the number of pulses in a train.

those in Figs 3(d) [27] and 3(e) [28] as the sensing layer is placed between different metal layers rather than on top of the upper metal layer.
To minimize the silicon area occupied, the sensing capacitor in Fig. 3(d) and 3(e) can be placed on top of the stimulator digital circuits. The structure in Fig. 3(e) was chosen because 


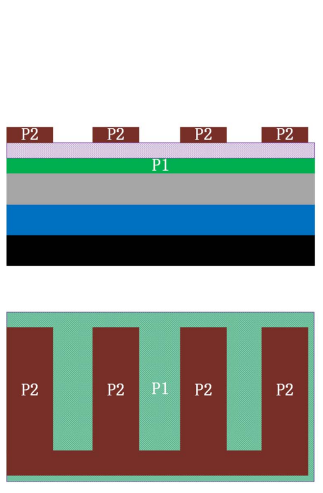

(a)

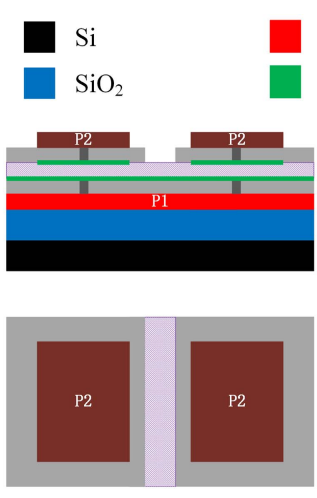

(b)

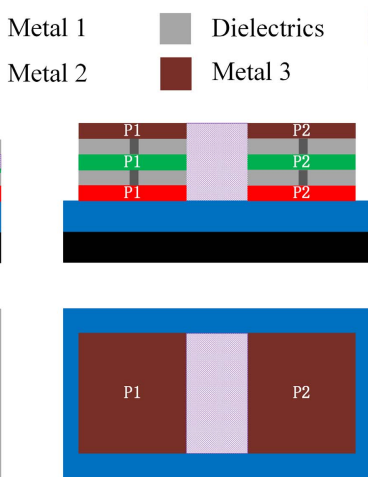

(c)
Sensing layer

VIA
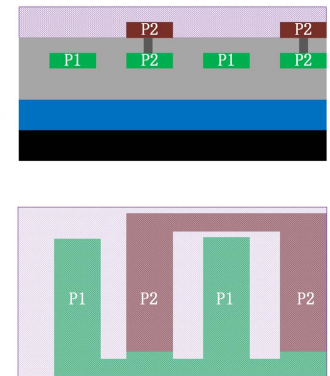

(d)
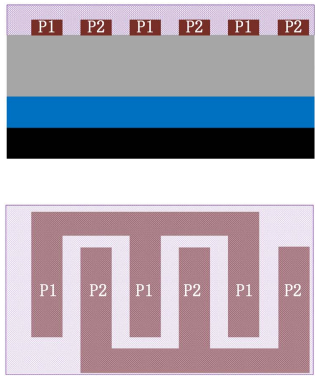

(e)

Fig. 3. Integrated capacitive humidity sensor topologies [cross-section view (first row) and top view (second row)] with the sensing layer placed in (a) and (b) between parallel-plate electrodes [22], [25], (c) between lateral electrodes [26], (d) on top of electrodes [27], and (e) on top of interdigitated electrodes [28].

TABLE II

Application of the Process Metal Layers in the Stimulator Chip

\begin{tabular}{|c|c|c|c|}
\hline Application & Metal 1 & Metal 2 & $\begin{array}{c}\text { Metal 3 } \\
\text { (top metal) } \\
\end{array}$ \\
\hline Within analog circuit blocks & $\checkmark$ & $\checkmark$ & \\
\hline Within digital cells & $\checkmark$ & $\checkmark$ & \\
\hline Interconnection for digital cells & $\checkmark$ & $\checkmark$ & \\
\hline Interconnection for analog blocks & $\checkmark$ & $\checkmark$ & \\
\hline Seal ring & & & $\checkmark$ \\
\hline Power ring for ESD & & $\checkmark$ & $\checkmark$ \\
\hline Humidity sensor & & & $\sqrt{ }$ \\
\hline IO pads & $\checkmark$ & $\checkmark$ & $\checkmark$ \\
\hline $\begin{array}{l}\text { Interconnection between IO pads and pre-buffers }{ }^{*} \text {, output buffers }{ }^{*} \text {, and ESD cells } \\
\text { (the routing needs to trespass the seal ring) }\end{array}$ & & $\checkmark$ & \\
\hline $\begin{array}{l}\text { Interconnection between core circuits and pre-buffers }{ }^{*}, \text { output buffers }{ }^{*} \text {, and ESD cells } \\
\text { (the routing needs to trespass the power rings) }\end{array}$ & $\checkmark$ & & \\
\hline
\end{tabular}

${ }^{*}$ These are located between the seal ring and the power ring.

it removes the availability of only one metal layer (Metal 3 in XFAB's XC06 process) and the remaining lower level metals (Metal 1 and Metal 2) are left for routing and interconnection of the circuit structures underneath the sensor. The polyimide (available in XC06), which is deposited on top of the passivation layer during the normal process flow, was used as the moisture sensitive layer. To avoid any post processing the passivation layer was not removed (at the expense of reduced sensitivity due to its presence between the top plate of the sensing capacitor and the sensing layer). An increase of moisture intake (humidity) increases the permittivity of the dielectric between the interdigitated electrodes, resulting in a higher capacitance. The capacitive sensor geometry was optimized following the procedure in [29]. Table II lists the application of the three metal layers in the XC06 process for the various stimulator components. The area of the digital circuits approximately doubles to $3.6 \mathrm{~mm}^{2}$ when omitting the top metal layer for routing (as demonstrated by the Cadence Encounter synthesis tool). Nevertheless, the area of the digital circuits is always smaller than that of the humidity sensor $\left(3.6 \mathrm{~mm}^{2}\right.$ vs. $\left.4 \mathrm{~mm}^{2}\right)$. Since the sensor was placed on top of the digital circuits they did not contribute towards the total area of the chip.

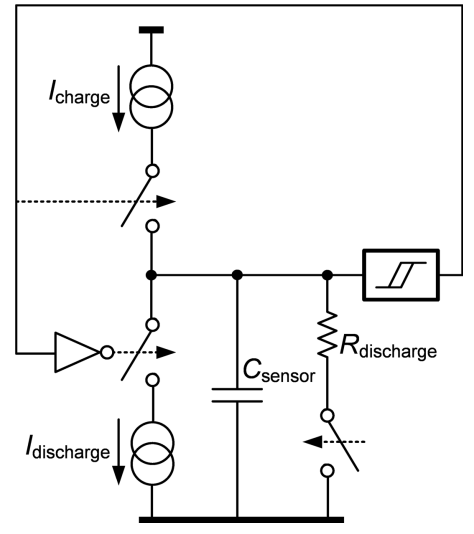

Fig. 4. Humidity sensor readout circuit. $C_{\text {sensor }}$ is a humidity-sensitive capacitor.

Fig. 4 shows the simplified schematic of the relaxation oscillator used to convert a change of capacitance to a change of frequency [30]. Currents $I_{\text {charge }}$ and $I_{\text {discharge }}$ (mirrored from the temperature-independent current reference, see Section IV) controlled by the Schmitt trigger, alternatively charge and discharge the sensing capacitor $\left(C_{\text {sensor }}\right)$. The circuit provides 


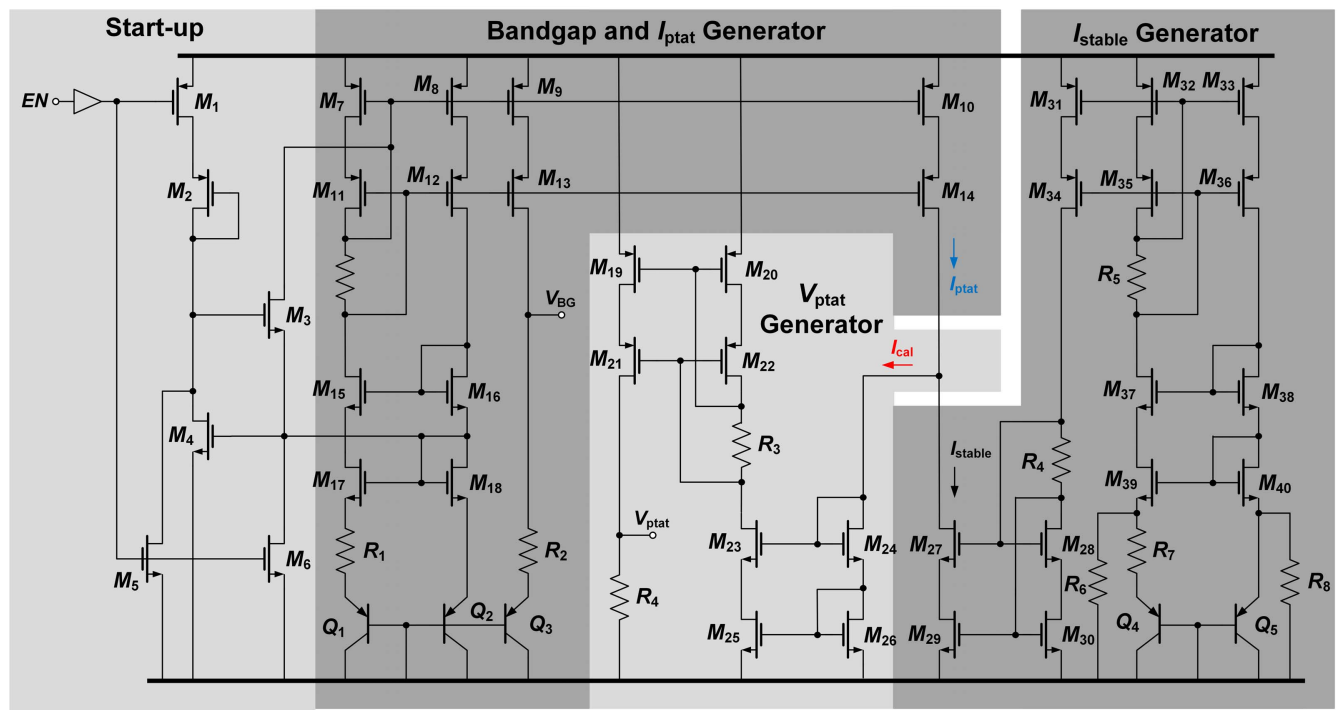

Fig. 5. Temperature sensor circuit.

a frequency $f$ that is inversely proportional to the value of $C_{\text {sensor }}$, and thus to the relative humidity (RH):

$$
f=\frac{I_{\text {charge } / \text { discharge }}}{2\left(V_{\mathrm{TH}}-V_{\mathrm{TL}}\right) C_{\text {sensor }}}
$$

where $V_{\mathrm{TH}}$ and $V_{\mathrm{TL}}$ are the high and low threshold voltage levels of the Schmitt trigger, respectively. $C_{\text {sensor }}$ has a positive dielectric coefficient against RH.

\section{TEMPERATURE SENSOR}

Fig. 5 shows the circuit diagram of the temperature sensor. It utilizes the fact that the base-emitter voltage of a bipolar junction transistor (BJT) is temperature dependent with a negative temperature coefficient (TC) of about $-2 \mathrm{mV} /{ }^{\circ} \mathrm{K}$. The circuit comprises: i) bandgap and $I_{\text {ptat }}$ generator, ii) $I_{\text {stable }}$ generator, and iii) $V_{\text {ptat }}$ generator. Transistors $Q_{1}-Q_{5}$ are standard vertical pnp BJTs available in an n-well CMOS process with their collectors always tied to the substrate.

The bandgap and $I_{\text {ptat }}$ generator produces a current which is proportional to absolute temperature. Current $I_{\text {ptat }}$ is given by

$$
I_{\text {ptat }}=\left(I_{C}\right)_{Q_{1}}=\frac{1}{R_{1}} \frac{k T}{q} \ln \left(\frac{\left(I_{C}\right)_{Q_{2}}}{\left(I_{C}\right)_{Q_{1}}} \frac{\left(I_{S}\right)_{Q_{1}}}{\left(I_{S}\right)_{Q_{2}}}\right)
$$

where $k$ is the Boltzmann's constant, $T$ is the temperature in Kelvin, $q$ is the electron charge, $I_{C}$ and $I_{S}$ are respectively the collector and saturation currents of a BJT. In the design

$$
\begin{aligned}
& \left(I_{C}\right)_{Q_{1}}:\left(I_{C}\right)_{Q_{2}}:\left(I_{C}\right)_{Q_{3}}=6: 11: 6, \\
& \left(I_{S}\right)_{Q_{1}}:\left(I_{S}\right)_{Q_{2}}:\left(I_{S}\right)_{Q_{3}}=5: 1: 1, \\
& R_{1}=10.42 \mathrm{k} \Omega \text { and } R_{2}=9.5 R_{1}
\end{aligned}
$$

and using (2) yields $I_{\text {ptat }}=(18.3 \mathrm{nA}) T$. The circuit also provides a temperature independent voltage, $V_{\mathrm{BG}}$, of $\sim 1.2 \mathrm{~V}$.

If $I_{\text {ptat }}$ flows through a resistor, the voltage across the resistor will, to a first order approximation, also be proportional to temperature in Kelvin. ${ }^{1}$ In practice, the temperature sensor measures the temperature of the stimulator chip

\footnotetext{
${ }^{1}$ The voltage across a resistor is only linear to temperature if the resistor has zero TC. In practice, a low TC polysilicon resistor was used. Its TC is only $-0.02 \% / \mathrm{K}$
}

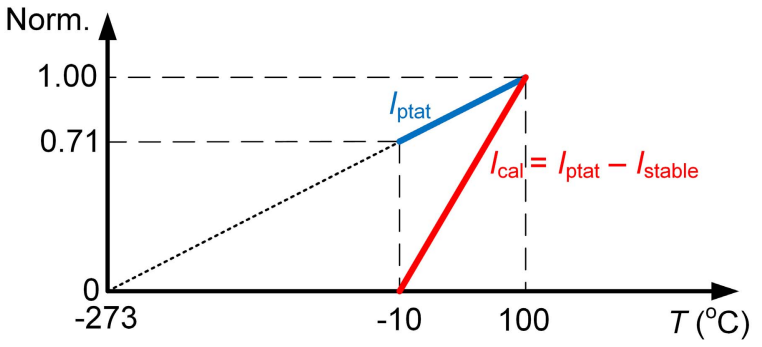

Fig. 6. Normalized currents $I_{\text {ptat }}$ and $I_{\text {cal }}$ vs. temperature.

whose micropackage [31] is surrounded by body fluid. In low power operation the surface temperature of the chip in an Active Book will be at near body temperature. The chip will dissipate increased heat when it is in high power operation (e.g., continuous stimulation at $8 \mathrm{~mA}$ ). To measure the operating temperature of the stimulator chip after device implantation, the temperature sensor must be able to sense accurately temperatures in the range of $35-40{ }^{\circ} \mathrm{C}$. In the design, the measurement range was extended $\left(-10{ }^{\circ} \mathrm{C}\right.$ to $\left.100{ }^{\circ} \mathrm{C}\right)$ to allow characterization of both the humidity and temperature sensors under a range of test conditions. As illustrated in Fig. 6, the range from $-10{ }^{\circ} \mathrm{C}$ to $100{ }^{\circ} \mathrm{C}$ only occupies $29.5 \%$ of the dynamic range from $-273{ }^{\circ} \mathrm{C}$ to $100{ }^{\circ} \mathrm{C}$. This was addressed by subtracting a temperature-independent current, $I_{\text {stable }}$, from current $I_{\text {ptat }}$ as shown in Fig. 6. Current $I_{\text {ptat }}$ becomes

$$
I_{\text {ptat }}=4.8 \mu \mathrm{A}+18.3 \mathrm{nA}\left(T-263{ }^{\circ} \mathrm{C}\right)
$$

where $4.8 \mu \mathrm{A}$ is the $I_{\text {ptat }}$ current at $-10{ }^{\circ} \mathrm{C}$. Using $I_{\text {stable }}=$ $4.8 \mu \mathrm{A}, I_{\text {cal }}$ can now target $100 \%$ of the dynamic range.

The $I_{\text {stable }}$ generator is highlighted in Fig. 5. Its start-up circuit is similar to that of the bandgap and $I_{\text {ptat }}$ generator and hence is omitted for simplicity. Current $I_{\text {stable is given by }}$

$$
\begin{aligned}
I_{\text {stable }} & =I_{M_{32}}=\frac{\left(V_{\mathrm{BE}}\right)_{Q_{5}}}{R_{6}}+\left(I_{C}\right)_{Q_{4}} \\
& =\frac{\left(V_{\mathrm{BE}}\right)_{Q_{5}}}{R_{6}}+\frac{1}{R_{7}} \frac{k T}{q} \ln \left(\frac{\left(I_{C}\right)_{Q_{5}}}{\left(I_{C}\right)_{Q_{4}}} \frac{\left(I_{S}\right)_{Q_{4}}}{\left(I_{S}\right)_{Q_{5}}}\right)
\end{aligned}
$$




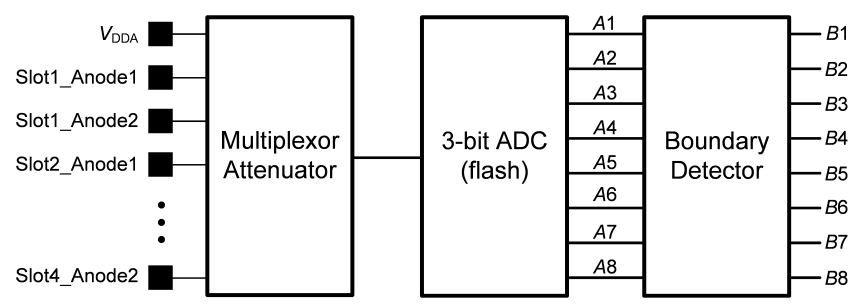

Fig. 7. Voltage sensor block diagram.

where the former and latter terms in (4) have negative and positive TCs, respectively and $I_{\text {stable }}$ can be compensated to almost zero TC. In the design, $\left(I_{C}\right)_{Q_{4}}:\left(I_{C}\right)_{Q_{5}}=1: 1,\left(I_{S}\right)_{Q_{4}}$ : $\left(I_{S}\right)_{Q 5}=5: 1, R_{7}=2 R_{1}, R_{6}=24 R_{1}$, and $R_{8}=24 R_{1}$.

Current $I_{\text {cal }}$ is applied to the $V_{\text {ptat }}$ generator which generates the temperature sensitive output voltage $V_{\text {ptat }}$, given by

$$
V_{\text {ptat }}=I_{\text {cal }} R_{4}
$$

where $V_{\text {ptat }}$ is digitized by a 10-bit SAR ADC (see Fig. 2).

\section{Voltage Sensor}

The chip measures the peak electrode voltage on any specified stimulating anode and sends the information to the central hub. If the voltage required to drive the electrode is much smaller than the supply voltage $V_{\mathrm{DDA}}$, the hub will adjust down its dc-dc converter output and send a smaller supply voltage to the chip on the Active Book to minimize power consumption and heat dissipation. If the electrode voltage is too close to $V_{\mathrm{DDA}}$ the electrode is either overcharged or it saturates at the current supply voltage which will raise alarm signals.

Fig. 7 shows the simplified block diagram of the voltage sensor. It comprises a Multiplexor-Attenuator, a 3-bit flash $\mathrm{ADC}$ and a Boundary Detector. Depending on the commands, either one of the eight anode electrode voltages or the supply voltage $\left(V_{\mathrm{DDA}}\right)$ is selected for measurement. Since the maximum supply voltage that can be sent to the stimulator chip is $18 \mathrm{~V}$, the attenuator (attenuation factor of 3.6 implemented by a resistive divider) ensures that the selected voltage can be processed by the $5 \mathrm{~V}$ circuits (ADC and Boundary Detector). The attenuated electrode voltage is then compared with 8 reference voltages using a flash-type ADC, categorizing the peak electrode into one of nine ranges. The voltage sensor uses a bubble boundary detector to check possible ADC errors or glitches. The exact timing of the measurement takes place during the last $2 \mu \mathrm{s}$ of the stimulus pulse, ensuring that the electrode voltage is sampled almost at its peak. Note that during the measurement phase, part of the stimulus current is lost to the voltage attenuator which is activated for $2 \mu \mathrm{s}$ only. The duration of this loss is much shorter that the stimulus pulse width ( $2 \mu \mathrm{s}$ vs. tens of microseconds) and the attenuator load is much larger than the electrode impedance $(402 \mathrm{k} \Omega$ vs. $\leq 2 \mathrm{k} \Omega$ ). This results in a negligible stimulation charge reduction. Table III lists the electrode voltage boundaries $(E l d)$ associated with the ADC digital outputs.

\section{Measured Results}

The stimulator was implemented using the XFAB 0.6$\mu \mathrm{m}$ HV CMOS process (XC06). Two different chips were
TABLE III

Possible Electrode Voltage Boundaries

\begin{tabular}{|c|c|c|}
\hline $\begin{array}{c}\text { ADC Output } \\
(\boldsymbol{A 1}-\boldsymbol{A 8})\end{array}$ & $\begin{array}{c}\text { Boundary Detector } \\
\text { Output }(\boldsymbol{B 1}-\boldsymbol{B 8})\end{array}$ & Condition \\
\hline 00000000 & 00000000 & Eld $>17.25 \mathrm{~V}$ \\
\hline 10000000 & 10000000 & $17.25 \mathrm{~V}>$ Eld $>15.75 \mathrm{~V}$ \\
\hline 11000000 & 01000000 & $15.75 \mathrm{~V}>$ Eld $>14.25 \mathrm{~V}$ \\
\hline 11100000 & 00100000 & $14.25 \mathrm{~V}>$ Eld $>12.75 \mathrm{~V}$ \\
\hline 11110000 & 00010000 & $12.75 \mathrm{~V}>$ Eld $>11.25 \mathrm{~V}$ \\
\hline 11111000 & 00001000 & $11.25 \mathrm{~V}>$ Eld $>9.75 \mathrm{~V}$ \\
\hline 11111100 & 00000100 & $9.75 \mathrm{~V}>$ Eld $>8.25 \mathrm{~V}$ \\
\hline 11111110 & 00000010 & $8.25 \mathrm{~V}>$ Eld $>6.75 \mathrm{~V}$ \\
\hline 11111111 & 00000001 & $6.75 \mathrm{~V}>$ Eld \\
\hline
\end{tabular}

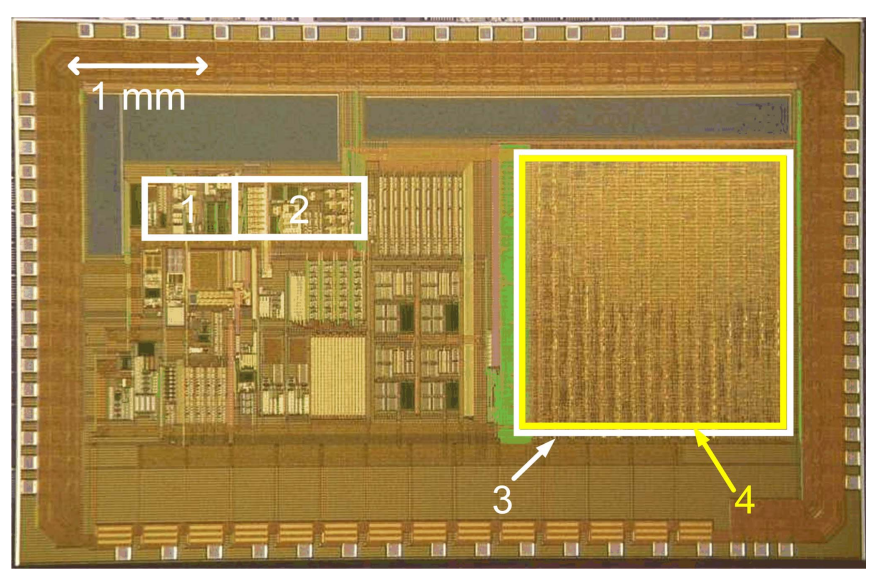

Fig. 8. Die photo of the stimulator chip. The marked areas show; 1: temperature sensor, 2: voltage sensor, 3: humidity sensor, 4: digital circuits.

fabricated: an implant chip and a test chip. The implant chip has minimum number of input and output (IO) pads (five IOs for cable connection and twelve IOs for connection to four tripolar electrodes). The test chip has additional IOs to facilitate testing of the various sub-circuits. Each stimulator chip drives a four-slot tripolar book electrode with each slot consisting of one central cathode flanked by two outer anodes.

Fig. 8 shows the die photo of the test chip from which the measured results were obtained. Five test chips were each wire bonded to a ceramic package (JLCC 68) for electrical testing. Fig. 9 is a cross-section image of the chip in the vicinity of the humidity sensor, showing the construction of the capacitive sensor using Metal 3 for the interdigitated electrodes, and its placement on top of the logic circuits using Metal 1 and Metal 2 for routing. Table IV lists some features and measured performance of the stimulator chip.

\section{A. Stimulation Performance}

Fig. 10 shows the capability of the stimulator chip to adjust the stimulus (cathode) current amplitude, to $0 \mathrm{~mA}, 1 \mathrm{~mA}$, $4 \mathrm{~mA}$, and $8 \mathrm{~mA}$ (the two anode currents are $0 \mathrm{~mA}, 0.5 \mathrm{~mA}$, $2 \mathrm{~mA}$ and $4 \mathrm{~mA}$ respectively). A $470 \Omega$ load resistor was used to monitor the current. The default (cathode) stimulus current amplitude is $1 \mathrm{~mA}$. The currents can be arbitrarily adjusted by sending appropriate pulse trains (see Table I) over the data lines. In Fig. 10, the variable current amplitude is evident in the "STIM" phase after the "PROG" phase programs the current amplitude to the desirable level. 


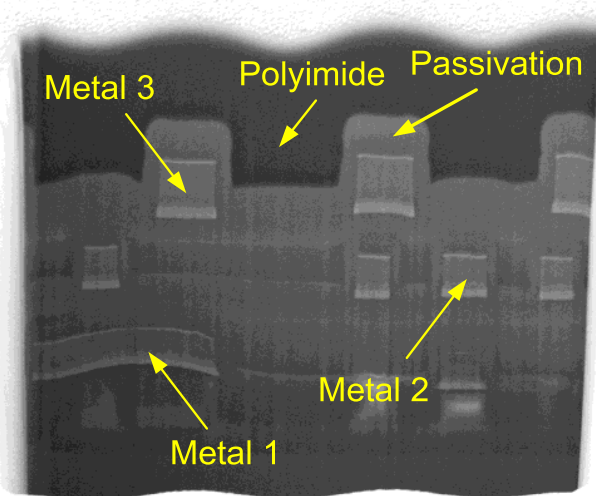

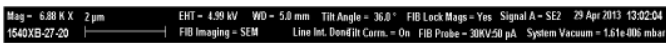

Fig. 9. Scanning electron microscope (SEM) image of the stimulator chip in the vicinity of the humidity sensor.

TABLE IV

Stimulator Chip Features and Measured Performance Summary

\begin{tabular}{|l|l|}
\hline Parameter & Value \\
\hline Technology & $0.6-\mu \mathrm{m} \mathrm{HV} \mathrm{CMOS}$ \\
\hline Supply voltage & $7.5-18 \mathrm{~V}$ \\
\hline Die size & $6.2 \times 4 \mathrm{~mm}^{2}$ \\
$\quad$ - Analog core & $3.1 \times 2.3 \mathrm{~mm}^{2}$ \\
$\quad$ * Temperature sensor & $0.4 \times 0.9 \mathrm{~mm}^{2}$ \\
$\quad$ - Voltage sensor & $0.9 \times 0.5 \mathrm{~mm}^{2}$ \\
- Digital core & $1.9 \times 1.9 \mathrm{~mm}^{2}$ \\
- Humidity sensor (on top of the & $2 \times 2 \mathrm{~mm}^{2}$ \\
\hline IO pads & \\
\hline Channels & $2 \times$ power, $3 \times$ data, $12 \times$ electrodes \\
\hline Stimulation & 4 tripoles \\
- Stimulus current amplitude & $1 \mathrm{~mA}, 4 \mathrm{~mA}$ or $8 \mathrm{~mA}$ \\
- Anode current ratio adjustment & $\pm 20 \%$ in steps of $2 \%$ \\
- Stimulus pulse duration & $2 \mu \mathrm{s}-1.07 \mathrm{~ms}$ \\
\hline Temperature sensor & \\
- Detectable range & $-10{ }^{\circ} \mathrm{C}-100^{\circ} \mathrm{C}$ \\
- Resolution & 924 steps \\
- Nonlinearity & $0.4 \%$ \\
- Power consumption & $245 \mu \mathrm{W}$ \\
\hline Humidity sensor & \\
- Detectable range & $0-100 \% \mathrm{RH}$ \\
- Resolution & $126 \mathrm{steps}$ \\
- Absolute sensitivity & $5 \mathrm{~Hz} / \% \mathrm{RH}$ \\
- Normalized sensitivity & $0.04 \% / \% \mathrm{RH}$ \\
- Temperature dependence & $0.9 \% \mathrm{RH} /{ }^{\circ} \mathrm{C}$ \\
- Power consumption & $180 \mu \mathrm{W}$ \\
\hline Voltage sensor & $0-18 \mathrm{~V}$ \\
- Detectable range & $9 \mathrm{steps}$ \\
- Resolution & $805 \mu \mathrm{W}$ \\
- Power consumption & \\
\hline
\end{tabular}

Fig. 11 shows the performance of the stimulator chip when used to drive an unbalanced tripolar book electrode (of the type described in [32]) in $0.9 \% \mathrm{NaCl}$ solution. The current through each anode was monitored by a floating-input differential probe (Pico Technology TA044) measuring the voltage across a $470 \Omega$ resistor placed in series with the anode electrode. By default, the two anode currents are equal as shown

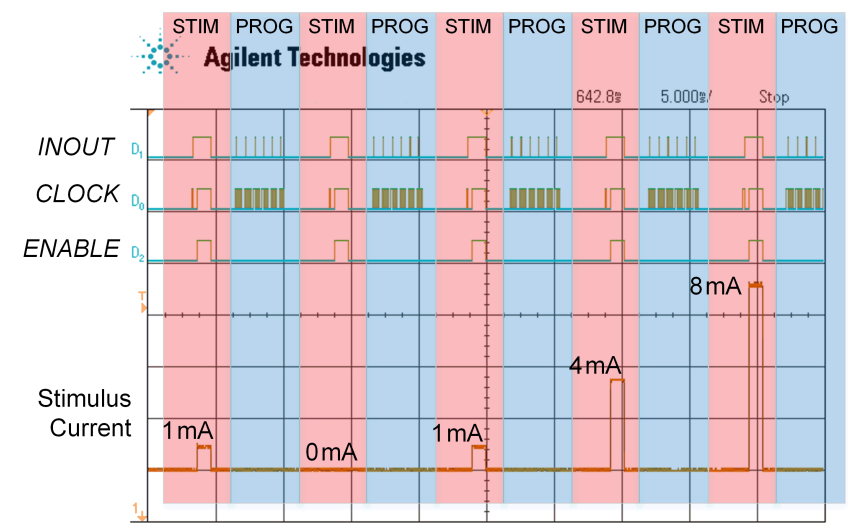

Fig. 10. Oscillogram showing change of stimulus current after receiving digital programming commands (INOUT, CLOCK and ENABLE lines).

\section{Agilent Technologies}

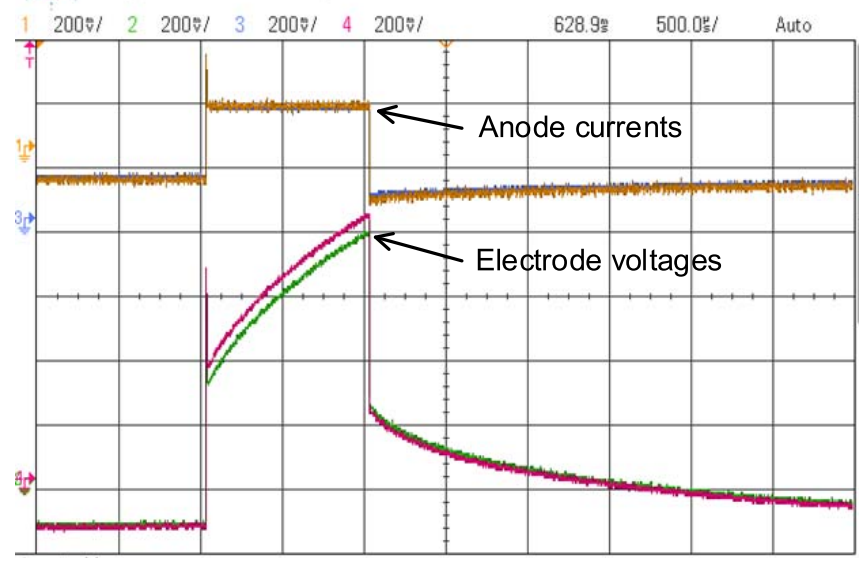

(a)

\section{Agilent Technologies}

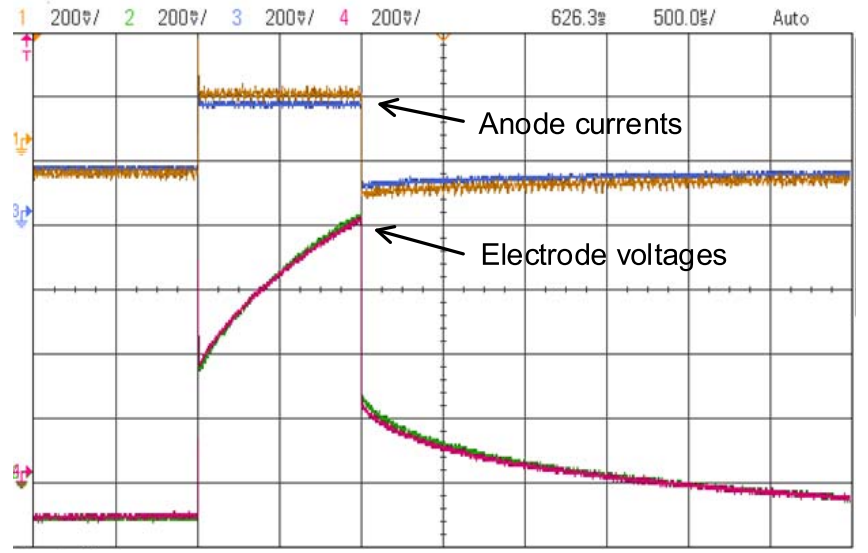

(b)

Fig. 11. Measured anode currents $\left(I_{\text {anode1 }}, I_{\text {anode2 }}\right)$ and the corresponding electrode voltages when driving an unbalanced tripolar book electrode with: (a) $I_{\text {anode2 }}=I_{\text {anode1 }}=0.5 \mathrm{~mA}$ and (b) $I_{\text {anode2 }}=1.14 I_{\text {anode } 1}$.

in Fig. 11(a) despite an impedance mismatch between the anode-cathode pairs. Hence, the electrode voltages on the two anodes within the tripole are not the same [see Fig. 11(a)]. Fig. 12 illustrates the consequence of the anode voltage mismatch: the voltage difference creates a fringing electric field outside the chosen tripole slot (Slot 1), potentially 


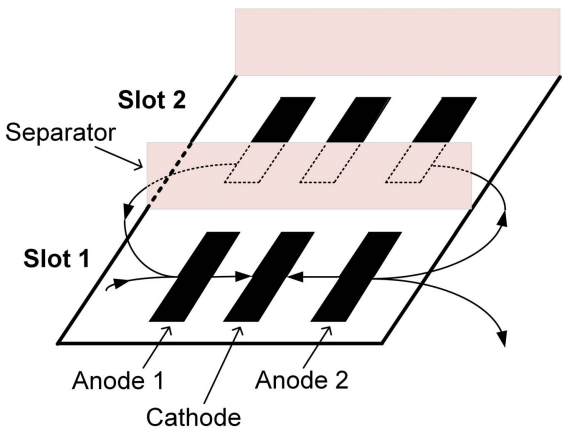

Fig. 12. Stimulation crosstalk caused by electrode impedance mismatch.
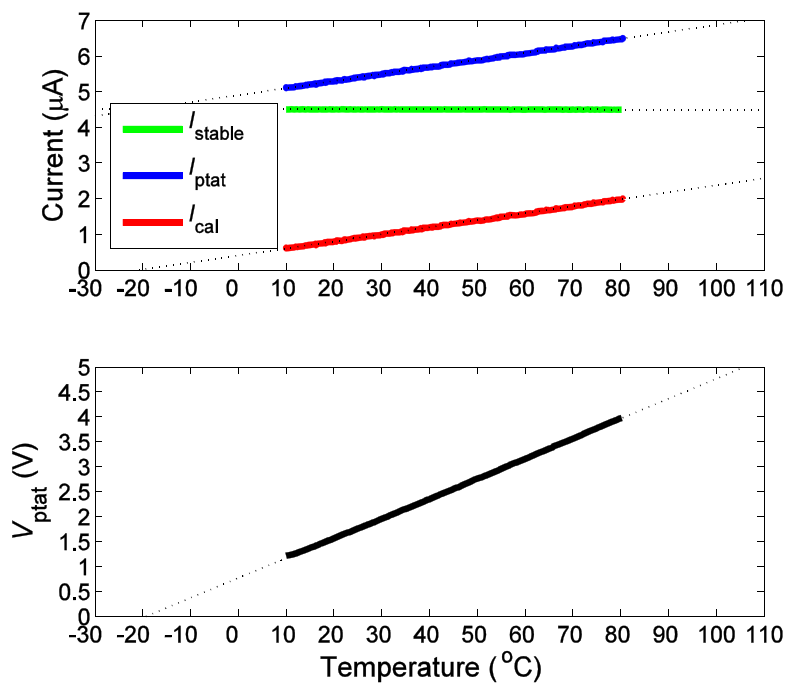

Fig. 13. Meaured temperature sensor signals $I_{\text {ptat }}, I_{\text {stable }}, I_{\text {cal }}$ and $V_{\text {ptat }}$ (see Fig. 5) versus temperature.

causing unintended stimulation in adjacent slots (i.e., Slot 2). Fig. 11(b) shows that by programming the $I_{\text {anode2 }} 14 \%$ higher than $I_{\text {anodel }}$, the difference between the two anode voltages can be nulled, hence reducing the crosstalk to adjacent slots.

\section{B. Temperature Sensor}

The performance of the temperature and humidity sensors were tested in a constant climate chamber (model KMF115, Binder GmbH [33]) which supports both temperature and humidity sweeps. The chip and a portable Binder Data Logger Kit TH-100 were placed inside the chamber. The TH-100 was placed very close to the stimulator chip to acquire the local temperature and humidity. The humidity was swept from $20 \%$ to $90 \%$ over a period of four hours. Both the temperature and humidity on-chip sensors have two sets of outputs, direct analog output and the corresponding digital output, which is modulated onto the INOUT line. For characterizing the analog outputs of the temperature sensor, a Keithley 6485 current meter and an Agilent 34401A 6-digit multimeter were used to measure current and voltage, respectively. Fig. 13 shows the measured analog outputs of the temperature sensor circuit in Fig. 5. The sensitivities of $I_{\text {ptat }}, I_{\text {stable }}$ and $V_{\text {ptat }}$ against temperature are $0.02 \mu \mathrm{A} /{ }^{\circ} \mathrm{C},-0.0001 \mu \mathrm{A} /{ }^{\circ} \mathrm{C}$ and $39 \mathrm{mV} /{ }^{\circ} \mathrm{C}$, respectively. Extrapolating $V_{\text {ptat }}$ to the full $0-5 \mathrm{~V}$ range, it should cover the temperature range of approximately $-20{ }^{\circ} \mathrm{C}$ to $105{ }^{\circ} \mathrm{C}$.

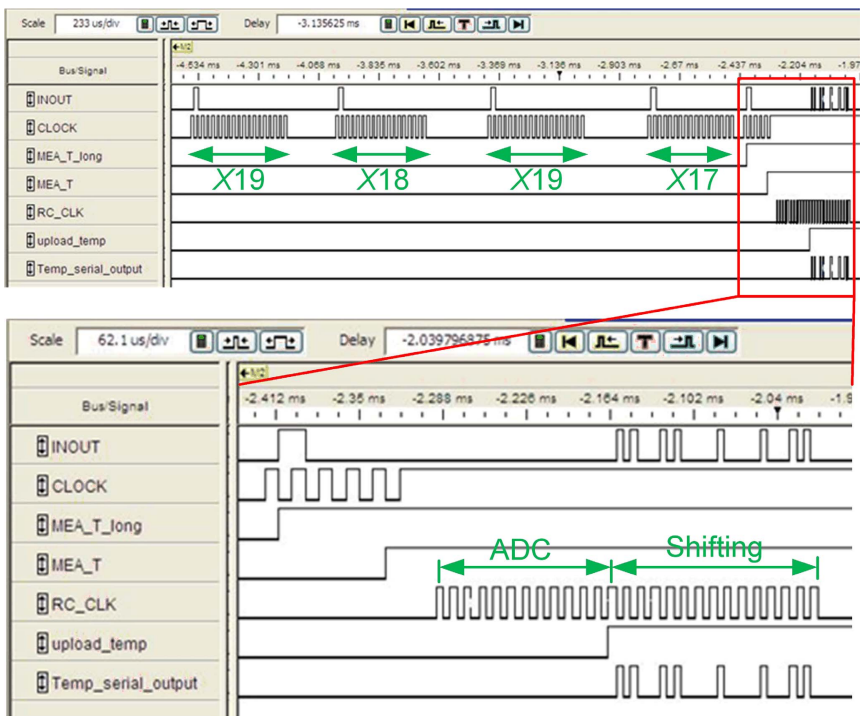

Fig. 14. Programming procedure for temperature measurement.

Fig. 14 illustrates the procedure to obtain a temperature reading (data captured by an Agilent 1334A logic analyzer). First, a measure temperature command, i.e., $X 19-X 18-X 19-X 17$, is sent to stimulator chip, after which $M E A \_T \_$long turns high, acknowledging receipt of the command and preparing the chip for the temperature measurement. Since the maximum temperature inside the implant micropackage is expected to occur when all four slots (tripoles) in the Active Book have experienced stimulation, the start of temperature measurement $\left(M E A_{-} T\right)$ occurs shortly after all slots have completed their stimulation (i.e., during the fifth pulse of the pulse train on the CLOCK line, and provided that MEA_T_long is high). In addition to instructing the sensor to take a temperature measurement, $M E A \_T$ starts an on-chip RC oscillator, which provides clock pulses $\left(R C \_C L K\right)$ necessary for driving the 10-bit SAR ADC and the 14-bit signal modulation (based on the constant-numberof-1s scheme as detailed in [24]) for transmission of the information on the INOUT line. The temperature information (Temp_serial_output) is then sent to the central hub.

The digital output of the temperature sensor was transferred to a National Instruments USB-6221 data acquisition card and converted to the corresponding analog value by a custom designed LabVIEW Virtual Instrument. Fig. 15 shows the temperature sensor performance for the five chips (normalized, giving zero output at $37{ }^{\circ} \mathrm{C}$ ). All sensors exhibit a linear relationship against temperature with a resolution of about $0.12{ }^{\circ} \mathrm{C}$ over the range of $20{ }^{\circ} \mathrm{C}$ to $90{ }^{\circ} \mathrm{C}$. The maximum nonlinearity over the entire temperature range is $0.4 \%$.

\section{Humidity Sensor}

To test the humidity sensor, the lid of each packaged chip was removed and the chip was placed inside the climate chamber at a constant temperature of $37^{\circ} \mathrm{C}$. The analog output of the humidity sensor, i.e., the variable output frequency of the oscillator, was recorded by an Agilent 53131A universal frequency counter. Fig. 16 shows the humidity sensor (normalized, giving zero output at $20 \% \mathrm{RH}$ ) output frequency against RH for the five chips. All five curves have a slope of 


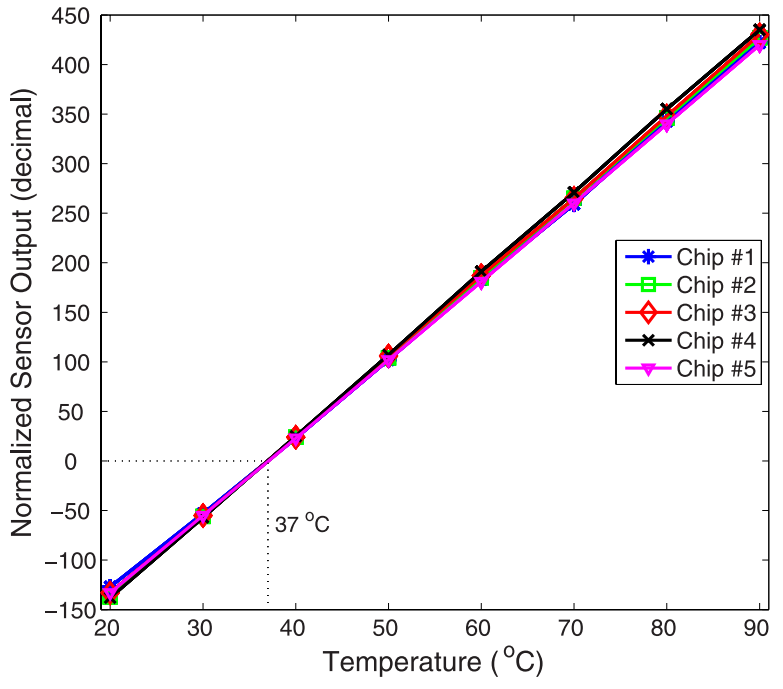

Fig. 15. Measured temperature sensor performance of five chips, normalized giving zero output at $37^{\circ} \mathrm{C}$.

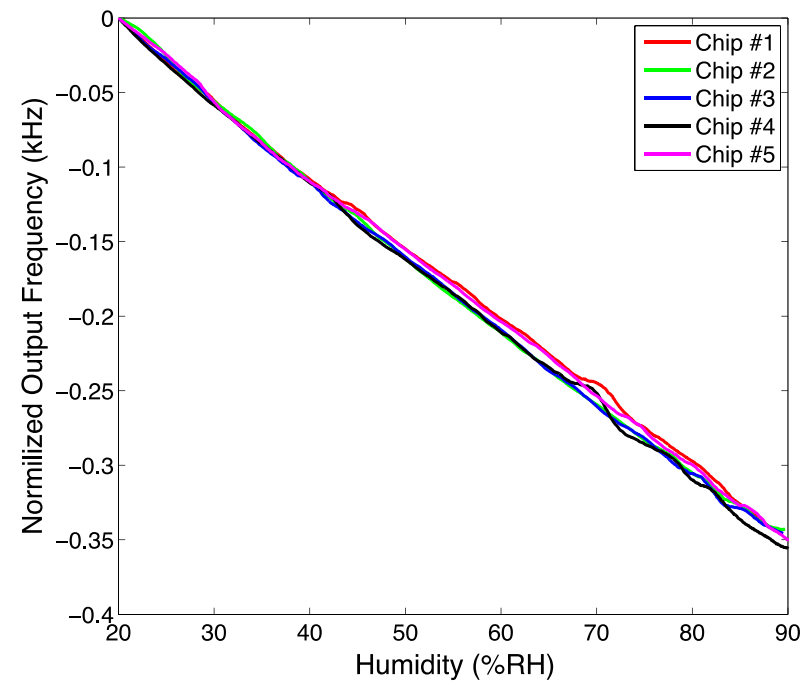

Fig. 16. Measured humidity sensor performance of five chips, normalized giving zero output at $20 \% \mathrm{RH}$.

about $5 \mathrm{~Hz} / \% \mathrm{RH}$, corresponding to a normalized sensitivity of $0.04 \% / \% \mathrm{RH}$. The low sensitivity of the sensor is attributed to the passivation layer which separates the Metal 3 interdigitated electrodes from the polyimide layer (see Fig. 9). The digital output of the humidity sensor comes from a counter-based ADC which counts the number of oscillation cycles within a given period. By adjusting the duration of the oscillation, small change of frequency can be detected.

Fig. 17 shows the variation of the humidity sensor output frequency over two weeks continuous operation when the humidity of the climate chamber was maintained constant at $32 \% \mathrm{RH}$ and the temperature at $37{ }^{\circ} \mathrm{C}$. The variation of the frequency is less than $0.1 \%$. If necessary it can be recalibrated by adjusting the duration of the oscillation (see below), which compensates for any drift over time.

Fig. 18 shows the procedure to obtain a humidity reading. Firstly, the train sequence $X 19-X 18-X 18-X 17$ starts the humidity sensor (MEA_RH signal turns high). It wakes up the on-chip oscillator (see Fig. 4) whose frequency is
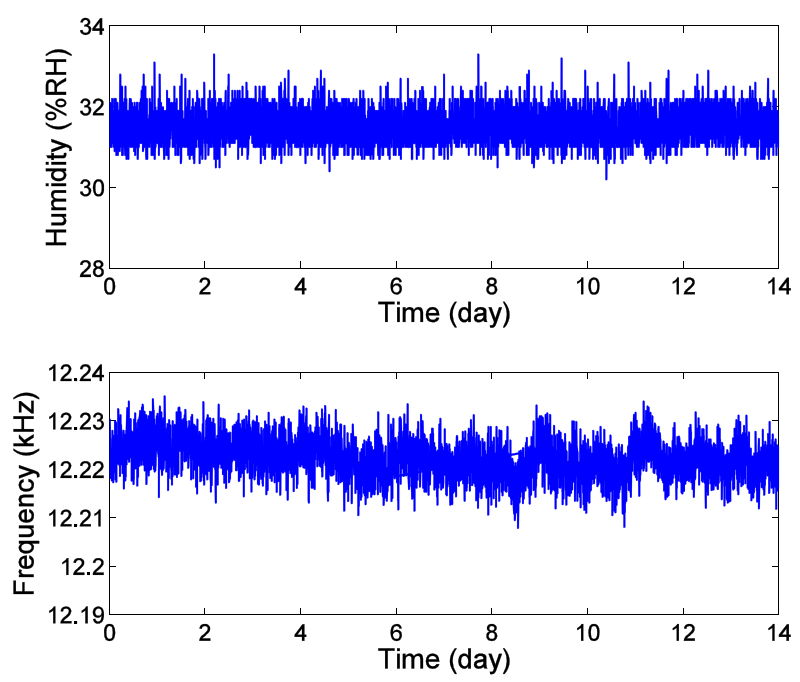

Fig. 17. Measured stability of humidity sensor output frequency over time (lower plot) at a constant climate chamber humidity and temperature of $32 \% \mathrm{RH}$ and $37^{\circ} \mathrm{C}$, respectively (upper lot).

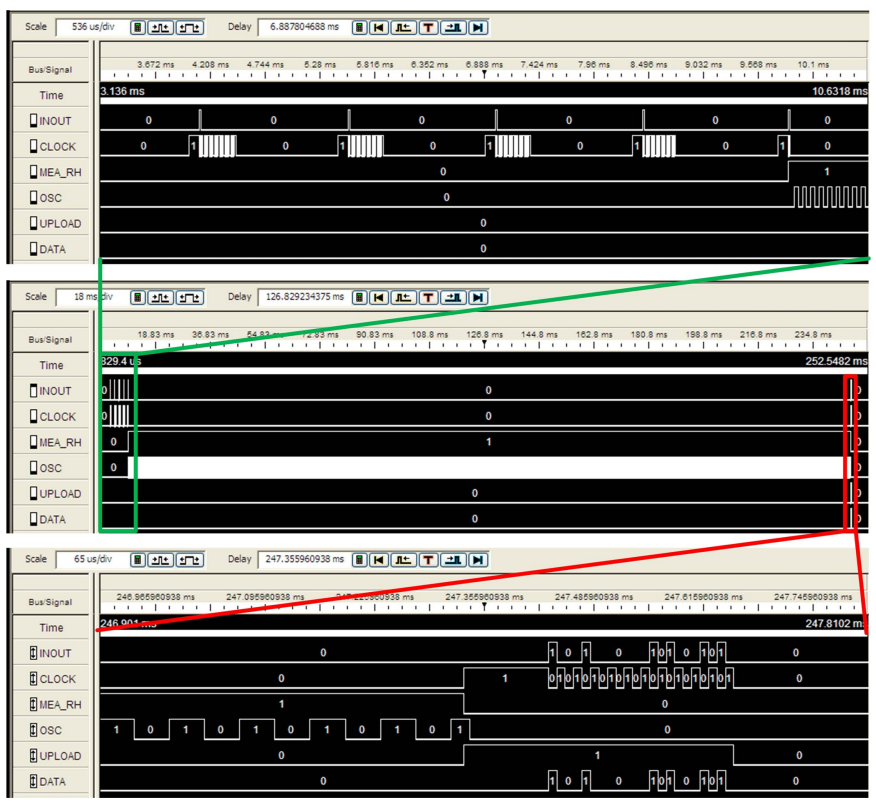

Fig. 18. Programming procedure for humidity measurement.

sensitive to humidity. The oscillator continues to oscillate until it is stopped by a pulse on the CLOCK line. The count number (i.e., the number of pulses on the $O S C$ line during the oscillation phase) is stored. Subsequent pulses on the CLOCK line interrogate the count information (see the DATA line), which is modulated on the INOUT line. By setting the duration of the oscillation phase to $238 \mathrm{~ms}$, the $30 \% \mathrm{RH}$ and $80 \% \mathrm{RH}$ humidities result in readings of 10111000101 (equivalent to 88 after demodulation) and 10100011011 (as shown in Fig. 18, equivalent to 25 after demodulation), respectively. This indicates that the minimum change of humidity that can be detected by the sensor is $(80 \% \mathrm{RH}-30 \% \mathrm{RH}) /(88-25)=0.79 \% \mathrm{RH}$. It is sufficient for monitoring the integrity of the implant package to provide an alarm when there are excessive changes in humidity within the implant package. 
TABLE V

COMPARISON OF INTEGRATED CAPACITIVE HUMIDITY SENSORS

\begin{tabular}{|c|c|c|c|c|c|c|}
\hline Reference & Sensor stucture & Sensing material & $\begin{array}{c}\text { Absolute } \\
\text { sensitivity }\end{array}$ & $\begin{array}{c}\text { Normalized } \\
\text { sensitivity }\end{array}$ & $\begin{array}{c}\text { Fabrication } \\
\text { post-processing }\end{array}$ & $\begin{array}{c}\text { Dedicated } \\
\text { sensor area }\end{array}$ \\
\hline$[25]$ & Parallel plate & Polymer & $\sim 43 \mathrm{fF} / \% \mathrm{RH}$ & $0.31 \% / \% \mathrm{RH}$ & Yes & Yes \\
\hline$[26]$ & Interdigitated & Polyimide & $16.4 \mathrm{kHz} / \% \mathrm{RH}$ & $\sim 0.03 \% / \% \mathrm{RH}$ & Yes & Yes \\
\hline$[34]$ & Parallel plate & Polyimide & $\sim 10 \mathrm{kHz} / \% \mathrm{RH}$ & $0.056 \% / \% \mathrm{RH}$ & Yes & Yes \\
\hline$[35]$ & Interdigitated & Polyimide & $1.46 \mathrm{fF} / \% \mathrm{RH}$ & $0.099 \% / \% \mathrm{RH}$ & Yes & Yes \\
\hline$[36]$ & Interdigitated & Polyimide & $5 \mathrm{fF} / \% \mathrm{RH}$ & $0.096 \% / \% \mathrm{RH}$ & Yes & Yes \\
\hline$[37]$ & Interdigitated & Polymer & $\sim 133 \mathrm{fF} / \% \mathrm{RH}$ & $\sim 0.25 \% / \% \mathrm{RH}$ & Yes & Yes \\
\hline This work & Interdigitated & Polyimide & $5 \mathrm{~Hz} / \% \mathrm{RH}$ & $0.04 \% / \% \mathrm{RH}$ & No & No \\
\hline
\end{tabular}

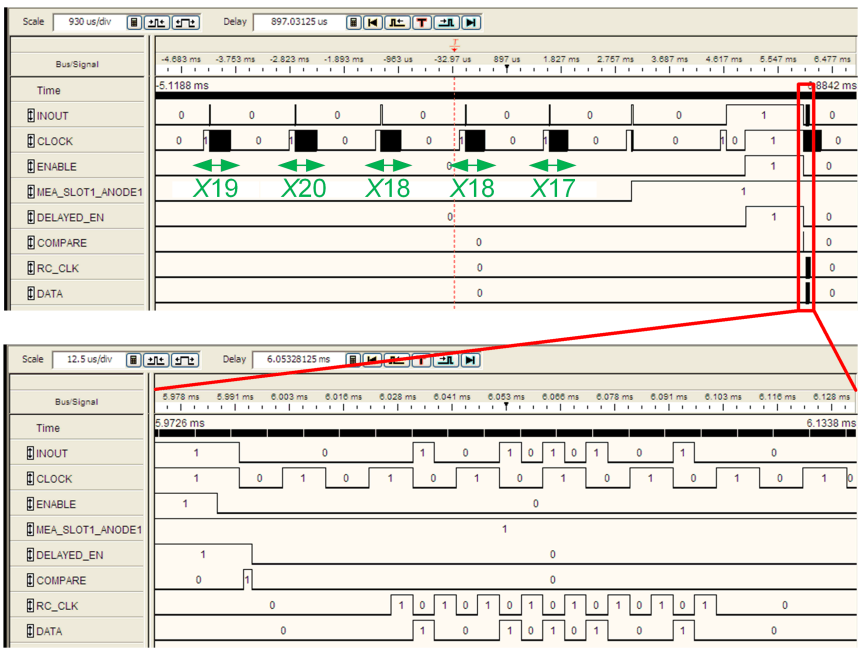

Fig. 19. Programming procedure for electrode voltage measurement.

Table V compares the humidity sensor with other work. The developed sensor features good performance with the added advantage that it is fully CMOS compatible and it does not use a dedicated area for the capacitive sensing element (which was placed on top of the digital circuits, see Figs. 8 and 9).

\section{Measurement of Electrode Voltage}

The Anode 1 of Slot 1 was selected for electrode voltage measurement (MEA_SLOT1_ANODE1 signal turning high in Fig. 19) when a pulse train sequence of $X 19-X 20-X 18-X 18-X 17$ was sent to the stimulator chip. The $E N A B L E$ signal from the central hub is $8 \mu$ s delayed, becoming the DELAYED_EN in Fig. 19. Stimulation takes place during the DELAYED_EN phase. As discussed in Section V the sampling of the anode electrode voltage takes place $2 \mu \mathrm{s}$ before the end of the stimulus pulse. Sampling exactly at the end of the ENABLE phase would be risky, as the ADC may erroneously capture the electrode voltage at the beginning of the passive discharge phase. Fig. 19 shows that information "1011101" was modulated back onto the INOUT line. After demodulation (explained in [24]) it can be deduced that the peak electrode voltage at the Anode 1 of Slot 1 is in the range of 6.75-8.25 V. For example, if the current supply voltage $\left(V_{\mathrm{DDA}}\right)$ were $18 \mathrm{~V}$, the measurement would indicate that a large portion of voltage headroom would be wasted.

\section{CONCLUSION}

To the authors' knowledge, this is the first paper on implantable stimulators that combines on-chip safety sensors for measuring humidity, temperature and electrode voltage, together with the stimulation circuits on a single chip using standard CMOS technology. The new stimulator offers enhanced safety for the Active Books microsystem. The sensors have been designed to monitor the operation of the implantable microsystem by triggering an alarm if the specified safety limits for humidity and temperature are exceeded, and to ensure that the stimulator is always operated with the minimum supply voltage. The data from the sensors can be communicated to a central hub for decision making, such as shutting down the device.

\section{REFERENCES}

[1] K. D. Wise, A. M. Sodagar, Y. Yao, M. N. Gulari, G. E. Perlin, and K. Najafi, "Microelectrodes, microelectronics, and implantable neural microsystems," in Proc. IEEE, vol. 96, no. 7, pp. 1184-1202, Jul. 2008.

[2] X. Liu, A. Demosthenous, and N. Donaldson, "An integrated stimulator with DC-isolation and fine current control for implanted nerve tripoles," IEEE J. Solid-State Circuits, vol. 46, no. 7, pp. 1701-1714, Jul. 2011.

[3] A. Rodriguez-Perez, J. Ruiz-Amaya, M. Delgado-Restituto, and Á. Rodriguez-Vazquez, "A low-power programmable neural spike detection channel with embedded calibration and data compression," IEEE Trans. Biomed. Circuits Syst., vol. 6, no. 2, pp. 87-100, Apr. 2012.

[4] M. S. Chae, Z. Yang, M. R. Yuce, L. Hoang, and W. Liu, "A 128-channel $6 \mathrm{~mW}$ wireless neural recording IC with spike feature extraction and UWB transmitter," IEEE Trans. Neural Syst. Rehabil. Eng., vol. 17, no. 4, pp. 312-321, Aug. 2009.

[5] A. Vanhoestenberghe and N. Donaldson, "Corrosion of silicon integrated circuits and lifetime predictions in implantable electronic devices," J. Neural Eng., vol. 10, no. 3, p. 031002, Jun. 2013.

[6] T. Cameron, T. L. Liinamaa, G. E. Loeb, and F. J. R. Richmond, "Longterm biocompatibility of a miniature stimulator implanted in feline hind limb muscles," IEEE Trans. Biomed. Eng., vol. 45, no. 8, pp. 1024-1035, Aug. 1998.

[7] M. Soma, "Reliability of implantable electronic devices: Two case studies," IEEE Trans. Rel., vol. 35, no. 5, pp. 483-487, Dec. 1986.

[8] P. D. Wolf, "Thermal considerations for the design of an implanted cortical brain-machine interface (BMI)," in Indwelling Neural Implants: Strategies for Contending With the in Vivo Environment. W. M. Reichert, Ed. Boca Raton, FL, USA: CRC Press, 2008, ch. 3.

[9] X. Liu, "Novel methods for fail-safe integrated neural stimulators," Ph.D. thesis, Dept. Electron. Elect. Eng., Univ. College London, London, U.K., 2009.

[10] N. Bhadra, K. L. Kilgore, and P. H. Peckham, "Implanted stimulators for restoration of function in spinal cord injury," Med. Eng. Phys., vol. 23, no. 1, pp. 19-28, Jan. 2001.

[11] F. Alesch, "Sudden failure of dual channel pulse generators," Movement Disorders, vol. 20, no. 1, pp. 64-66, Jan. 2005.

[12] G. S. Brindley, "The first 500 sacral anterior root stimulators: Implant failures and their repair," Paraplegia, vol. 33, no. 1, pp. 5-9, 1995.

[13] B. Kaczer, R. Degraeve, M. Rasras, K. Van de Mieroop, P. J. Roussel, and G. Groeseneken, "Impact of MOSFET gate oxide breakdown on digital circuit operation and reliability," IEEE Trans. Electron Devices, vol. 49, no. 3, pp. 500-506, Mar. 2002.

[14] H. Yang, J. S. Yuan, Y. Liu, and E. Xiao, "Effect of gate-oxide breakdown on RF performance," IEEE Trans. Device Mater. Rel., vol. 3 , no. 3, pp. 93-97, Sep. 2003. 
[15] G. Tognola, M. Parazzini, F. Sibella, A. Paglialonga, and P. Ravazzani, "Electromagnetic interference and cochlear implants," Annali dell'Istituto Superiore di Sanita, vol. 43, no. 3, pp. 241-247, 2007.

[16] P. W. Proctor and R. L. Dow, "Device for protecting an electronic prosthesis from adverse effects of RF and/or electrostatic energy," U.S. Patent 5197468, Mar. 30, 1993.

[17] T. Klenzner et al., "Influence of ionizing radiation on nucleus 24 cochlear implants," Otol. Neurotol., vol. 26, no. 4, pp. 661-667, Jun. 2005.

[18] A. Ralston, G. Stevens, E. Mahomudally, I. Ibrahim, and E. Leckie, "Cochlear implants: Response to therapeutic irradiation," Int. J. Radiat. Oncol. Biol. Phys., vol. 44, no. 1, pp. 227-231, Apr. 1999.

[19] P. S. Ruggera, D. M. Witters, G. V. Maltzahn, and H. I. Bassen, "In vitro assessment of tissue heating near metallic medical implants by exposure to pulsed radio frequency diathermy," Phys. Med. Biol., vol. 48, no. 17, pp. 2919-2928, Sep. 2003.

[20] C. Q. Huang, P. M. Carter, and R. K. Shepherd, "Stimulus induced $\mathrm{pH}$ changes in cochlear implants: An in vitro and in vivo study," Ann. Biomed. Eng., vol. 29, no. 9, pp. 791-802, Sep. 2001.

[21] X. Liu, A. Demosthenous, and N. Donaldson, "Implantable stimulator failures: Causes, outcomes, and solutions," in Proc. 29th Ann. Int. Conf. IEEE Eng. Med. Biol. Soc., Aug. 2007, pp. 5786-5789.

[22] M. Dokmeci and K. Najafi, "A high-sensitivity polyimide capacitive relative humidity sensor for monitoring anodically bonded hermetic micropackages," J. Microelectromech. Syst., vol. 10, no. 2, pp. 197-204, Jun. 2001

[23] C. Donfack, M. Sawan, and Y. Savaria, "Implantable measurement technique dedicated to the monitoring of electrode-nerve contact in bladder stimulator," Med. Biol. Eng. Comput., vol. 38, no. 4 , pp. 465-468, Jul. 2000.

[24] X. Liu, A. Demosthenous, A. Vanhoestenberghe, D. Jiang, and N. Donaldson, "Active Books: The design of an implantable stimulator that minimizes cable count using integrated circuits very close to electrodes," IEEE Trans. Biomed. Circuits Syst., vol. 6, no. 3, pp. 216-227, Jun. 2012

[25] N. Lazarus and G. K. Fedder, "Integrated vertical parallel-plate capacitive humidity sensor," J. Micromech. Microeng., vol. 21, no. 6, p. 065028, Jun. 2011

[26] C.-L. Dai, "A capacitive humidity sensor integrated with micro heater and ring oscillator circuit fabricated by CMOS-MEMS technique," Sens. Actuators B, Chem., vol. 122, no. 2, pp. 375-380, Mar. 2007.

[27] C. Hagleitner, D. Lange, A. Hierlemann, O. Brand, and H. Baltes, "CMOS single-chip gas detection system comprising capacitive, calorimetric and mass-sensitive microsensors," IEEE J. Solid-State Circuits, vol. 37, no. 12 , pp. $1867-1878$, Dec. 2002

[28] Z. Tan, R. Daamen, A. Humbert, Y. V. Ponomarev, Y. Chae, and M. A. P. Pertijs, "A 1.2-V 8.3-nJ CMOS humidity sensor for RFID applications," IEEE J. Solid-State Circuits, vol. 48, no. 10, pp. 2469-2477, Oct. 2013

[29] N. Saeidi, J. Strutwolf, A. Maréchal, A. Demosthenous, and N. Donaldson, "A capacitive humidity sensor suitable for CMOS integration," IEEE Sensors J., vol. 13, no. 11, pp. 4487-4495, Nov. 2013.

[30] D. Cirmirakis, A. Demosthenous, N. Saeidi, and N. Donaldson, "Humidity-to-frequency sensor in CMOS technology with wireless readout," IEEE Sensors J., vol. 13, no. 3, pp. 900-908, Mar. 2013.

[31] N. Saeidi, M. Schuettler, A. Demosthenous, and N. Donaldson, "Technology for integrated circuit micropackages for neural interfaces, based on gold-silicon wafer bonding," J. Micromech. Microeng., vol. 23, no. 7, p. 075021, Jul. 2013.

[32] I. Pachnis, A. Demosthenous, and N. Donaldson, "Passive neutralization of myoelectric interference from neural recording tripoles," IEEE Trans. Biomed. Eng., vol. 54, no. 6, pp. 1067-1074, Jun. 2007.

[33] Accessed on Jun. 17, 2016. [Online]. Available: http://www.binder-world com/en/Products/Constant-climate-chambers/Series-KMF/KMF-115

[34] T. J. Harpster, S. Hauvespre, M. R. Dokmeci, and K. Najafi, "A passive humidity monitoring system for in situ remote wireless testing of micropackages," J. Microelectromech. Syst., vol. 11, no. 1, pp. 61-67, Feb. 2002.

[35] C.-L. Zhao, M. Qin, and Q.-A. Huang, "A fully packaged CMOS interdigital capacitive humidity sensor with polysilicon heaters," IEEE Sensors J., vol. 11, no. 11, pp. 2986-2992, Nov. 2011.

[36] L. Gu, Q.-A. Huang, and M. Qin, "A novel capacitive-type humidity sensor using CMOS fabrication technology," Sens. Actuators B, Chem., vol. 99, nos. 2-3, pp. 491-498, May 2004

[37] C. L. Roozeboom et al., "Integrated multifunctional environmental sensors," J. Microelectromech. Syst., vol. 22, no. 3, pp. 779-793, Jun. 2013 .

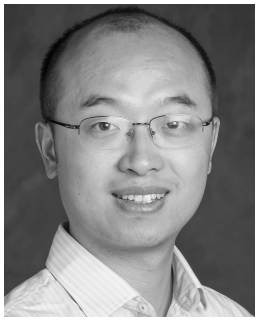

Xiao Liu (S'05-M'09) received the B.Eng. degree in information engineering from Xi' an Jiaotong University, Xi'an, China, in 2003, the M.Sc. degree in microelectronics systems design from the University of Southampton, Southampton, U.K., in 2004, and the Ph.D. degree from University College London (UCL), London, U.K., in 2009. From 2009 to 2011, he was a Post-Doctoral Research Associate with the Analog and Biomedical Electronics Group, UCL. From 2011 to 2013, he was a Lecturer with the School of Engineering and Design, Brunel University, London, U.K. He is currently a Lecturer with the Department of Electronic and Electrical Engineering, UCL. His main research interests include analog and mixed-signal circuit design for biomedical applications, neuroprostheses, microelectronic sensors, and wearable technologies.

Dr. Liu is an Associate Editor of the IEEE TRANSACTIONS ON Circuits AND Systems I: Regular PAPERS. He is a Chartered Engineer and a member of the Biomedical Circuits and Systems Technical Committee of the IEEE Circuits and Systems Society.

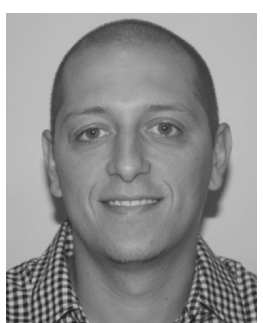

Virgilio Valente (S'09-M'11) was born in Milan, Italy, in 1979. He received the B.Sc. degree in electronic engineering from the University of York, York, U.K., in 2004, the M.Sc. degree in biomedical engineering from Aalborg University, Aalborg, Denmark, in 2006, and the Ph.D. degree in electronic and electrical engineering from University College London (UCL), London, U.K., in 2011. His $\mathrm{Ph} . \mathrm{D}$. dissertation was in the field of novel deep brain stimulator design. A patent was granted to him as a result of his research work on the application of phased array systems to deep brain stimulation. In 2010, he was appointed as a Research Associate with the Analog and Biomedical Electronics Research Group, UCL. His research interests include the design of analog and mixedsignal integrated circuits, for low-power biomedical systems, sensor interfaces and smart telemetry systems.

Dr. Valente is a member of the Biomedical Circuits and Systems Technical Committee of the IEEE Circuits and Systems Society.

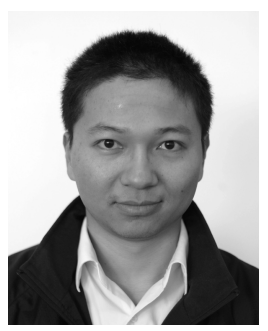

Zhulin Zong (S'08-M'12) was born in Nanchang, China, in 1983. He received the B.Eng. degree in microelectronics from Sichuan University, Chengdu, China, in 2003, and the M.Sc. degree in signal processing and the $\mathrm{Ph} . \mathrm{D}$. degree in communications and information systems from the University of Electronic Science and Technology of China (UESTC), Chengdu, in 2007 and 2012, respectively. From 2014 to 2015, he was a Visiting Post-Doctoral Scholar with the Department of Electronic and Electrical Engineering, University College London, London, U.K. He is currently an Associate Research Fellow with UESTC. His research interests are related to digital integrated circuit design and real-time signal processing for radar, communications, and biomedical applications.

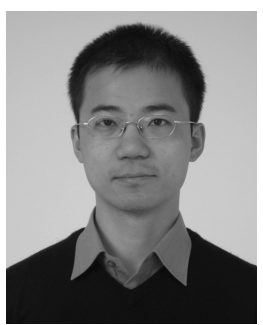

Dai Jiang (S'07-M'09) received the B.Sc. and M.Sc. degree from the Beijing University of Aeronautics and Astronautics, China, in 1998 and 2001, respectively, and the Ph.D. degree from University College London (UCL), U.K., in 2009. His Ph.D. work was on frequency synthesis. He was with the Datang Telecom Group, China, from 2001 to 2002, working on developing FPGA functions for WCDMA signal processing. From 2006 to 2008, he was a Research Assistant, and a Post-doctoral Research Associate since 2009, both with the Analog and Biomedical Electronics Group, UCL. His research interests include CMOS analog and mixed-signal integrated circuit design for biomedical applications.

Dr. Jiang is a member of the Biomedical Circuits and Systems Technical Committee of the IEEE Circuits and Systems Society. 


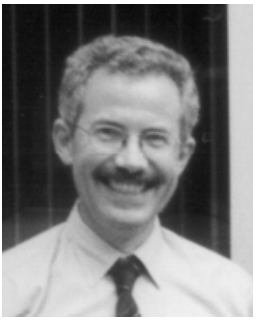

Nick Donaldson received the M.A. degree in engineering and electrical sciences from Cambridge University, Cambridge, U.K, in 1976, and the Ph.D. degree from University College London (UCL), London, U.K., in 1990. From 1977 to 1992 , he was with the Medical Research Council, Neurological Prostheses Unit, London, under the direction of Prof. G. S. Brindley. In that period, his main field of research was the technology and use of implanted devices for the restoration of useful leg function to paraplegics. Since 1992, he has been with the Department of Medical Physics and Bioengineering, UCL, where he is a Professor and leads the Implanted Devices Group. His research interests include the development of implanted devices that use natural nerve signals as inputs, especially for preventing incontinence, stimulators of nerve roots, the use of electrical stimulation for recreational exercise of paralyzed legs and methods to encourage functional neurological recovery after injury.

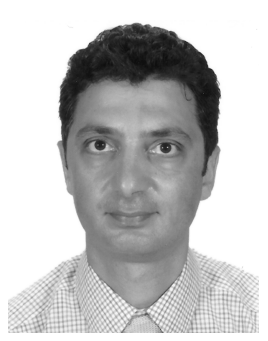

Andreas Demosthenous (S'94-M'99-SM'05) received the B.Eng. degree in electrical and electronic engineering from the University of Leicester, Leicester, U.K., in 1992, the M.Sc. degree in telecommunications technology from Aston University, Birmingham, U.K., in 1994, and the Ph.D. degree in electronic and electrical engineering from University College London (UCL), London, U.K., in 1998. He is a Professor with the Department of Electronic and

Electrical Engineering, UCL, where he leads the Analog and Biomedical Electronics Group. He has published over 250 articles in journals and international conference proceedings. His research interests include analog and mixed-signal integrated circuits for biomedical, sensor, and signal-processing applications.

Dr. Demosthenous is the Editor-in-Chief of the IEEE TRANSACTIONS ON Circuits AND Systems I: Regular PAPERs and an Associate Editor of the IEEE TRANSACTIONS ON BIOMEDICAL CiRCUITS AND Systems. He is a member of the Technical Program Committee of several IEEE conferences, including ESSCIRC and ISCAS. He is a Fellow of the Institution of Engineering and Technology and a Chartered Engineer. 